\title{
Neonatal pulmonary arteriovenous malformation in hereditary haemorrhagic telangiectasia
}

\author{
S Koppen, C R W Korver, M Dalinghaus, C J J Westermann
}

Arch Dis Child Fetal Neonatal Ed 2002;87:F226-F227

A 3 week old infant presented with persistent hypoxaemia and was diagnosed with pulmonary arteriovenous malformations. Her family history was positive for hereditary haemorrhagic telangiectasia. She was treated successfully with coil embolotherapy at the age of 4 months. Transcatheter embolisation may be considered the primary treatment for pulmonary arteriovenous malformations in infancy.

$\mathrm{H}$ ereditary haemorrhagic telangiectasia (HHT), also known as Rendu-Osler-Weber syndrome, is an autosomal dominant mucocutaneous and visceral vascular dysplasia, characterised by the occurrence of telangiectasia and arteriovenous malformations (AVMs). Patients are usually recognised by the presence of telangiectasia, recurrent epistaxis, and a positive family history. Clinical symptoms usually appear after puberty.

First reports appear to be from around 1864 when Sutton and Babington described patients with recurrent epistaxis and vascular abnormalities. Rendu, Osler, and Weber later recognised the combination of epistaxis in a familial pattern with telangiectasia. Pulmonary AVM is the most dangerous localisation of HHT because of the risk of paradoxical septic embolism. ${ }^{1}$ In 1897, the first pulmonary AVM was found at the postmortem examination of a 12 year old boy. ${ }^{2}$ Reported series of patients with pulmonary AVM, however, indicate that such findings are uncommon in children..$^{3-6}$ To our knowledge, only 12 cases of pulmonary AVM diagnosed during the first year of life have been described from 1975 onwards, the last one being reported in 2000. ${ }^{6}$ Most of the previously described cases were treated primarily with surgery. We report on a 3 week old infant who presented with persistent hypoxaemia as a result of pulmonary AVM.

\section{CASE REPORT}

A 3 week old Dutch Antillean girl was admitted after an apparently life threatening event. The pregnancy was uncomplicated, and the patient was born term with a birth weight of $2420 \mathrm{~g} \mathrm{(p13).} \mathrm{Apgar} \mathrm{scores} \mathrm{were} 8$ and 9 after one and five minutes respectively. There had been no remarkable events until the day of admission, when she had an apnoeic episode after several coughs. The pregnancy had been the mother's seventh. Two older children originate from another relationship; four pregnancies were terminated by legal abortion. The history later revealed the occurrence of HHT in the family, with a confirmed mutation in the gene coding for endoglin on chromosome 9 . This family, 3655, and the mutation have been described previously. ${ }^{7}$ The patient's mother has been diagnosed recently with HHT, and the presence of the same mutation is under investigation.

Physical examination at admission showed a healthy and alert black neonate without fever. Besides mild tachypnoea and a persistent percutaneous oxygen saturation of $87 \%$, vital signs were stable. Auscultation of the chest showed normal heart sounds with a slight early systolic murmur, maximal at the upper left sternal border, attributed to a persistent ductus arteriosus as evidenced by cardiac ultrasonography. On revision three weeks later, it was no longer audible or detectable. Over the posterior left lower lobe, a soft $2 / 6$ holosystolic bruit was audible, but otherwise lung sounds were normal. Liver and spleen were not enlarged. Otherwise, physical examination was unremarkable and no telangiectasies were found.

Laboratory examination showed a normal full blood count with normal values for serum electrolytes and glucose. The chest radiograph showed a hazy density in the left lower lobe, and spiral computed tomography using contrast showed an AVM measuring $2 \times 3 \mathrm{~cm}$ in the left lower lobe. Cerebral ultrasound was normal. The patient was referred to a tertiary centre for therapeutic intervention at the age of 4 months.

Cardiac catheterisation was performed under general anaesthesia with an $\mathrm{FIO}_{2}$ of 0.30 . Oximetry showed normal oxygen saturations in the right upper and lower and left upper pulmonary veins, suggesting that no pulmonary AVMs were present in the pulmonary lobes draining into these veins. In contrast, the oxygen saturation in the lower left pulmonary vein $(61 \%)$ was similar to the saturation of the blood entering the pulmonary circulation, indicating no functional contribution of the left lower lobe to gas exchange. Pulmonary angiography disclosed a diffuse complex pulmonary AVM with three feeding arteries in the left lower lobe without signs of pulmonary AVM in other lobes of the lung. The pulmonary AVM was successfully closed using four 3 and 5 mm PDA coils (Cook, Bjaeverskov, Denmark). Arterial oxygen saturation, as measured by pulse oximetry, instantly increased from $75-80 \%$ to $98 \%$ and has remained above $95 \%$ during follow up of nine months. The patient was discharged in good clinical condition 4 days after the intervention, and follow up has so far been unremarkable.

\section{DISCUSSION}

HHT remains a clinical diagnosis despite identification of two genes that cause the disease when mutated (endoglin and ALK-1). ${ }^{1}$ The four clinical diagnostic criteria (epistaxis, telangiectasia, visceral lesions, and a positive family history) have been clearly defined. ${ }^{8}$ The diagnosis of HHT is definite when three criteria are present, but cannot be established when only two are present. These patients, however, have a high index of clinical suspicion and should be carefully examined for other subtle manifestations of this disease. In children, the diagnosis of HHT is difficult because of age related development of HHT. In our patient, only two criteria were met (visceral lesions and positive family history of HHT

Abbreviations: $\mathrm{HHT}$, hereditary haemorrhagic telangiectasia; AVM, arteriovenous malformation 
in a first degree relative), and the presence of the mutated gene coding for endoglin on chromosome 9, as has been described in her family, ${ }^{7}$ was recently confirmed. Therefore, we consider her pulmonary AVM to be an expression of the same disease.

We report on one of the youngest patients diagnosed with a pulmonary AVM causing a large right to left shunt. The indication for treatment of the pulmonary AVM was persistent hypoxaemia as well as to prevent neurological sequelae caused by embolic disease. ${ }^{1}$ Until the 1980s, the classical treatment for pulmonary AVM was surgery. Since then, embolotherapy using coils or balloons has become the treatment of choice. ${ }^{59}$ Transcatheter coil embolisation of a large pulmonary AVM has been reported once before in a neonate. ${ }^{10}$ This approach is feasible for the treatment of large pulmonary AVMs in infancy, provided that it is performed by a paediatric cardiologist. Arguments favouring surgical intervention are the complexity of the pulmonary AVM and the extent of these lesions, leaving relatively little healthy pulmonary tissue sacrificed in the case of resection of the lobe. In our patient, embolisation was performed because of the selectiveness of the procedure and to avoid the disadvantages of major surgical intervention at this age. Transcatheter embolisation may be considered the primary treatment of pulmonary AVMs in infancy, depending on the angioarchitecture, but long term results of this procedure have to be awaited. Continuing surveillance is necessary to detect short term and long term recurrence, as well as potential development of other pulmonary AVMs, in order to prevent future neurological complications, such as stroke and brain abscess.

\section{Authors' affiliations}

S Koppen, C R W Korver, Department of Pediatrics, Kennemer Gasthuis, Haarlem, The Netherlands

M Dalinghaus, Department of Pediatrics, Division of Pediatric

Cardiology, Sophia Children's Hospital, University Hospital Rotterdam,

Rotterdam, The Netherlands

C J J Westermann, Department of Pulmonology, St Antonius Ziekenhuis, Nieuwegein, The Netherlands

Correspondence to: Dr Korver, Kennemer Gasthuis, PO Box 1638, 2003 BR Haarlem, The Netherlands; korver@kg.nl

Accepted 6 May 2002

\section{REFERENCES}

1 Guttmacher AE, Marchuk DA, White RI Jr. Hereditary hemorrhagic telangiectasia. N Engl J Med 1995;333:918-24.

2 Churton T. Multiple aneurysms of pulmonary artery. BM 1897;1:1223.

3 Dines DE, Seward JB, Bernatz PE. Pulmonary arteriovenous fistulas. Mayo Clin Proc 1983:58:176-81.

4 Puskas JD, Allen MS, Moncure AC, et al. Pulmonary arteriovenous malformations: therapeutic options. Ann Thorac Surg 1993;56:253-8.

5 Pick A, Deschamps C, Stanson AW. Pulmonary arteriovenous fistula: presentation, diagnosis and treatment. World J Surg 1999;23:1118-21. 6 Faughnan ME, Lui YW, Wirth JA, et al. Diffuse pulmonary arteriovenous malformations. Chest 2000;117:31-3.

7 Gallione CJ, Scheessele EA, Reinhardt D, et al. Two common endoglin mutations in families with hereditary hemorrhagic telangiectasia in the Netherlands Antilles: evidence for a founder effect. Hum Genet 2000;107:40-4.

8 Shovlin CL, Guttmacher AE, Buscarini E, et al. Diagnostic criteria for hereditary hemorrhagic telangiectasia (Rendu-Osler-Weber syndrome) Am J Med Genet 2000;91:66-7.

9 Haitjema T, Westermann CJ, Overtoom TC, et al. Hereditary hemorrhagic telangiectasia (Osler-Weber-Rendu disease): new insights in pathogenesis, complications and treatment. Arch Intern Med 1996:156:714-19.

10 Grady RM, Sharkey AM, Bridges ND. Transcatheter coil embolisation of a pulmonary arteriovenous malformation in a neonate. Br Heart $J$ 1994:71:370-1.

\section{IMAGES IN NEONATAL MEDICINE}

\section{Natal and neonatal teeth}

T

he incidence of natal and neonatal teeth varies from $1: 1000$ to $1: 30000 .^{1}$ There are

no reports in extreme preterm babies.

A baby born at 24 weeks gestation in our neonatal unit had one natal tooth at the region of the lower central incisors (the most common site) (fig 1). It fell out within two weeks without causing any complications.

The teeth can be either a premature eruption of the normal teeth (up to 95\%) or supernumerary $(5 \%){ }^{2}$ The cause is not known. There are no reports in the literature about the actual occurrence of aspiration.

Natal teeth may be removed only if they are extremely mobile. ${ }^{2}$ Supernumerary teeth need extraction if confirmed by radiography. ${ }^{1}$

\section{R Sureshkumar}

A H McAulay

Department of Paediatrics, Poole Hospital, Poole BH15 2JB, Dorset, UK; drrsuresh@aol.com

\section{References}

1 Cunha R, Carrilho Boer F, Torriani DD, et al. Natal and neonatal teeth: review of literature. Pediatr Dent 2001;23:158-62.

2 Kates G, Needleman H, Holmes LB, et al. Natal and neonatal teeth: a clinical study. J Am Dent Assoc 1984;109;441-3.
Arch Dis Child Fetal Neonatal Ed 2002;87:F227

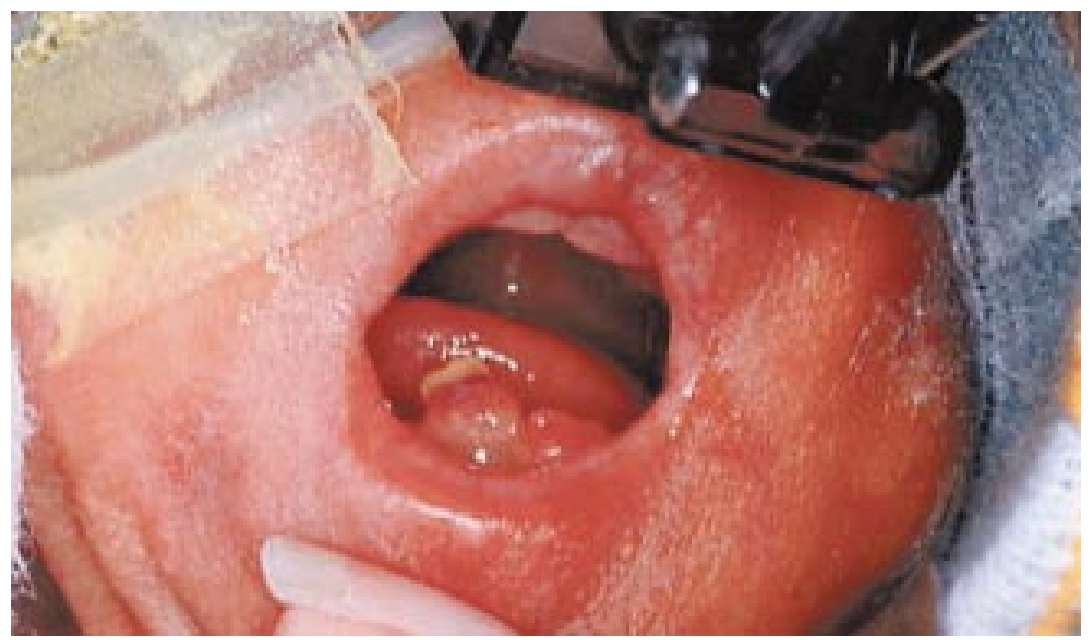

Figure 1 Baby born at 24 weeks gestation with one natal tooth. 